MATHEUS CARNEIRO LIMA

\title{
STANDARDS DE PROVA NO DIREITO BRASILEIRO
}

Dissertação de Mestrado

Professor Orientador: Kazuo Watanabe

FACULDADE DE DIREITO DA UNIVERSIDADE DE SÃO PAULO

São Paulo - SP

2018 
Dissertação de Mestrado apresentada ao Departamento de Direito Processual ("DPC") da Faculdade de Direito da Universidade de São Paulo, como requisito parcial para a obtenção do grau de Mestre, sob orientação do Orientador: Professor Kazuo Watanabe.

FACULDADE DE DIREITO DA UNIVERSIDADE DE SÃO PAULO São Paulo - SP 
Catalogaçăo da Publicaçăo

Serviço de Biblioteca e Documentação

Faculdade de Direito da Universidade de São Paulo

Lima, Matheus

Standards de prova no direito brasileiro / Matheus Lima ; orientador Kazuo Watanabe -- São Paulo, 2018.

128

Dissertacão (Mestrado - Programa de Pós-Graduacão em Direito Processual) - Faculdade de Direito, Universidade de São Paulo, 2018.

1. Processo civil. 2. Prova judicial. 3. Direito comparado. I. Watanabe, Kazuo, orient. II. Título. 


\section{MATHEUS CARNEIRO LIMA}

Standards de prova no direito brasileiro

Dissertação de Mestrado apresentada ao Departamento de Direito Processual ("DPC") da Faculdade de Direito da Universidade de São Paulo, como requisito parcial para a obtenção do grau de Mestre, sob orientação do Professor Dr. Kazuo Watanabe.

Aprovado em:

BANCA EXAMINADORA

Prof. (a):

Julgamento:

Prof. (a):

Julgamento:

Prof. (a):

Julgamento:
Instituição:

Assinatura:

Instituição:

Assinatura:

Instituição:

Assinatura: 


\section{AGRADECIMENTOS}

Em primeiro lugar, e acima de tudo, gostaria de agradecer a meus pais, Cristóvão e Luciana, por todos os esforços empreendidos em minha educação e por acreditarem em meus sonhos, possibilitando meu ingresso no mestrado e me dando amor e suporte desde o início de minha vida. Além desses, agradeço também a meus irmãos, apesar de todas as dificuldades de convivência, e em especial a meu tio e padrinho Marcelo, que sempre foi uma inspiração para seguir na área acadêmica, e minha afilhada Sofia, que apesar da distância é sempre uma alegria em minha vida.

Em seguida, tenho que agradecer também à família que construí em São Paulo. Primeiramente, para meu Orientador, Professor Kazuo Watanabe, que acreditou em mim mesmo quando estava em fase de descoberta do meu novo tema, e vem me acompanhando até este momento. Em seguida, ao Professor Paulo Lucon, João Paulo Hecker e Ronaldo Vasconcelos, amigos e mestres que me acolheram no escritório Lucon Advogados, sem os quais não conseguiria desenvolver minha pesquisa a esse nível.

Também devo agradecer a todos os amigos que me ofereceram suporte e me suportaram durante todo esse período, tanto os que trouxe desde o Maranhão, principalmente Diogo Diniz, Rafaela Sodré, Rafael Bezerra Nunes e Orlando Guterres, como os que fiz nessa nova etapa de minha vida, especialmente Daniel Campos, Frederico Sabbag, Mateus Bessa, André Orthmann, Max Fischer, Danilo Cronemberger e Luis Fernando Matricardi.

Por último e não menos importante, aos amigos e coorientados Diego Caldo, Claudio Oliveira, Jean Carlo Bispo e Mario Aufiero, grupo que dividiu todas as vitórias e angústias desse período de pós-graduação. 
"There is always, in litigation, a margin of error, representing error in factfinding, which both parties must take into account." (William J. Brennan Jr., Speiser v. Randall, 357 U.S. 525526) 


\section{RESUMO}

LIMA, Matheus Carneiro. Standards de prova no direito brasileiro. 2018. 132 p. Dissertação (Mestrado em Direito Processual) - Faculdade de Direito da Universidade de São Paulo, São Paulo, 2018.

A atividade jurisdicional é indissociável das decisões sobre questões de fato, assim como dos erros nessas decisões. Os ordenamentos jurídicos de common law, reconhecendo tal premissa, utilizam os standards de prova como mecanismos de distribuição ou controle do custo desses erros. O presente trabalho busca demonstrar que as mesmas bases que fundamentam a aplicação de standards de prova no direito estrangeiro são aplicáveis ao direito brasileiro, onde standards existem mas não são estudados como tal. Isso será realizado a partir da análise dos fundamentos políticos, normativos e psicológicos dos standards de prova, além de sua formulação em outros ordenamentos jurídicos, para extrair fundamentos generalizáveis e aplicáveis ao direito brasileiro. Além disso, demonstramos que a própria análise do ônus da prova pode se dar de forma distinta a partir dos standards de prova, indo além da distinção entre seu caráter objetivo e subjetivo.

Palavras-chave: Processo Civil. Prova. Elementos de prova. Standard de prova. Ônus da prova. 


\begin{abstract}
LIMA, Matheus Carneiro. Standards of proof in brazilian law. 2018. 132 p. Dissertation (Master of Law) - Faculdade de Direito da Universidade de São Paulo, São Paulo, 2018.

The jurisdictional activity is inseparable from decisions on issues of fact, and also from the errors in these decisions. The common law legal systems, recognizing this premise, adopt the standards of proof as a mechanism to distribute or control the cost of these errors. The present dissertation aims to demonstrate that the basis for the application of standards of proof in foreign legal systems are also applicable to Brazilian law, where there are already standards, but they are not classified as such. This will be achieved by the analysis of the political, normative and psychological grounds of the standards of proof, and by the study of their formulation in other legal systems, to extract general grounds applicable to brazilian law. Also, we demonstrate that the analysis of the burden of proof can be made differently from the standards of proof, going beyond the distinction between its subjective and objective characters.
\end{abstract}

Key words: Civil Procedure. Proof. Evidence. Standard of proof. Burden of Proof. 


\section{Lista de Gráficos}

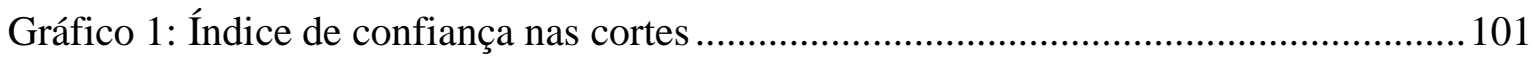




\section{Sumário}

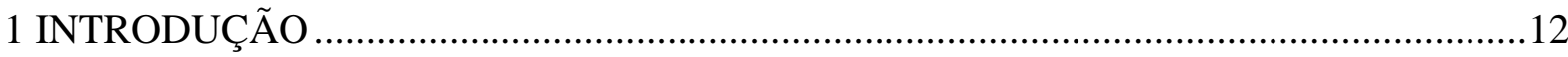

1.1 Tema a ser desenvolvido e suas limitações ............................................................... 12

1.2 Justificativa da escolha e da importância do tema ...................................................... 12

1.3 Principais questões a serem analisadas ................................................................... 17

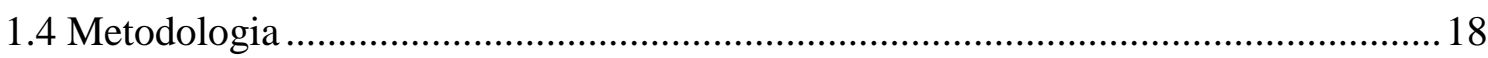

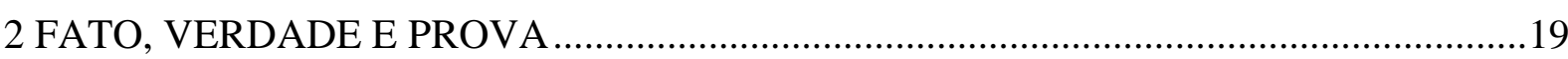

2.1 Fato, verdade, e a aplicação do direito................................................................. 19

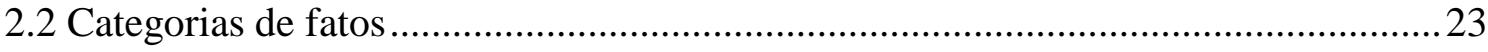

2.3 Teorias da verdade e sua aplicação ao processo ………………………………….......25

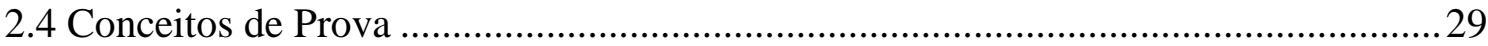

3 PARÂMETROS DE SUFICIÊNCIA PROBATÓRIA: OS STANDARDS DE PROVA.....32

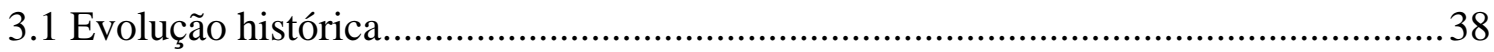

3.2 Da livre apreciação da prova e da prova legal ......................................................... 42

3.3 Standards de prova: A experiência americana ...........................................................4

3.3.1 Prova além da dúvida razoável ........................................................................48

3.3.3. Preponderância da evidência ..............................................................................56

3.4 Um exemplo da civil law: o beweisma $\beta$ alemão.......................................................... 61

3.5 Aspectos políticos e normativos dos standards de prova..............................................65

3.5.1 Prevenção de falsos positivos - O standard da dúvida razoável.................................65

3.5.2 Minimização do custo dos erros - A preponderância da evidência...........................69

3.5.3 Dificuldade da prova.......................................................................................

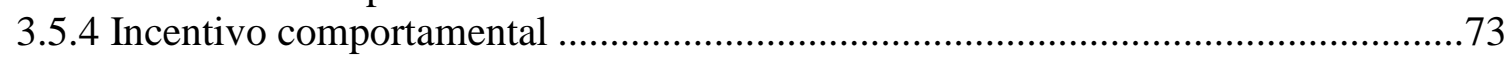

3.6 Aspectos psicológicos dos standards de prova. ..................................................... 73

3.6.1 Julgadores leigos e profissionais? ……………………………………………...74

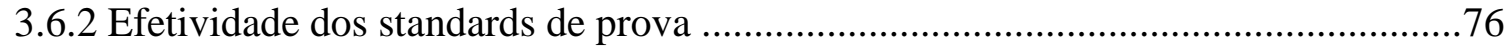

3.6.3 Modelos coarse scale e sliding scale ....................................................................

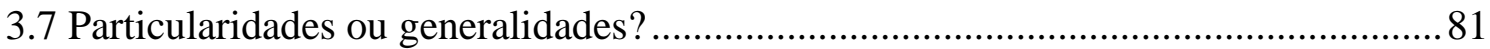

4 STANDARDS DE PROVA NO DIREITO BRASILEIRO ………….................................83

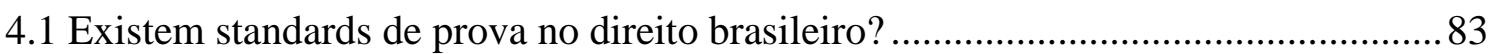

$4.2 \mathrm{O}$ fumus boni iuris, o periculum in mora, e a verossimilhança da alegação antes do

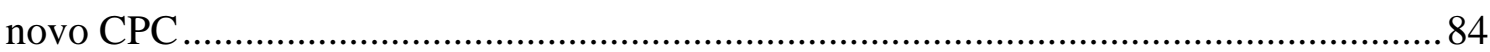

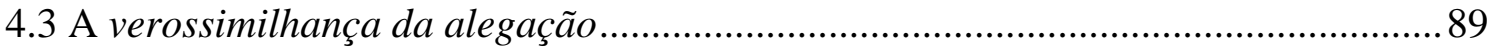

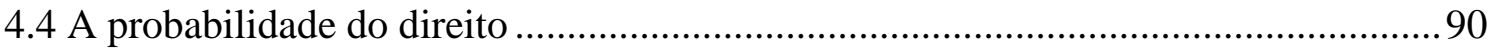

4.5 As tutelas de urgência e a preponderância da evidência.................................................91

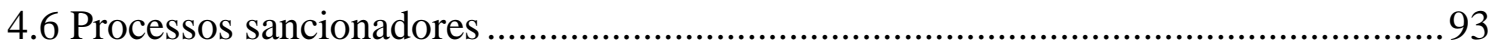

5 STANDARDS DE PROVA E ÔNUS DA PROVA …………………………….............104

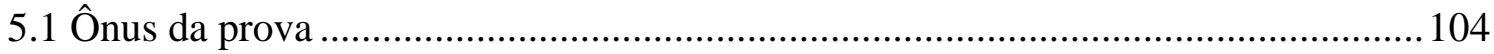


5.2 Os aspectos do ônus da prova: Subjetivo e Objetivo.............................................. 106

5.3 Ônus da produção e ônus da persuasão .................................................................... 108

5.4 Standards de prova e julgamento por ônus da prova ............................................. 111

5.4.1 Julgamento por ônus da produção ........................................................................112

5.4.2 Ônus da persuasão, standard de prova e julgamento por ônus da prova ................115

5.5 Distribuição dinâmica do ônus da prova e standards de prova................................... 116

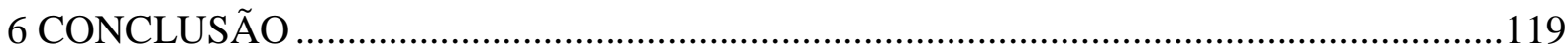

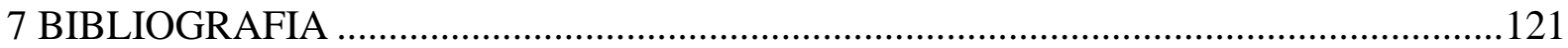




\section{INTRODUÇÃO}

\subsection{Tema a ser desenvolvido e suas limitações}

O presente trabalho visa analisar a viabilidade e existência de parâmetros de suficiência probatória no direito brasileiro, a partir da criação de standards de prova, utilizando o modelo de direito processual de raízes continentais (civil law) adotado no Brasil, além de analisar seu impacto no instituto do ônus da prova.

A partir da análise da origem dos standards de prova, além das diferentes fundamentações e justificações que o instituto possui em diversos ordenamentos, tanto em sistemas de civil law e common law, o presente trabalho busca identificar suas características e parâmetros mais básicos, para a partir deles justificar a adoção do instituto no direito brasileiro, e identificar os standards já existentes em nosso ordenamento (ainda que sob denominações distintas).

O presente trabalho não busca indicar com precisão a extensão exata que os standards a ser adotados tomarão, porque tal medida dependeria de uma construção jurisprudencial que ainda não foi concretizada, além da análise de critérios de política legislativa do direito material que vão além do escopo do presente trabalho.

A hipótese a ser desenvolvida no presente trabalho é a de que existem dois fundamentos principais dos standards de prova que transcendem os sistemas de common law onde o instituto se originou, e podem justificar a adoção do instituto no direito brasileiro: a) a minimização do custo dos erros sobre decisões de fato; e b) os mecanismos psicológicos que orientam a tomada de decisões;

Por se tratarem não de imposições legais sobre prova, mas de critérios de racionalidade nas decisões sobre questões de fato, os standards criados a partir desses fundamentos principais são perfeitamente compatíveis com uma perspectiva moderna do convencimento judicial, que apesar de adotar um sistema de liberdade da prova superou a intime conviction.

E, a partir da análise da suficiência probatória, também se propõe uma releitura do instituto do ônus da prova, que propõe a análise dos conceitos de "ônus da produção" e “ônus da persuasão", e seus impactos nas decisões baseadas nas regras de ônus da prova.

\subsection{Justificativa da escolha e da importância do tema}


É praticamente unânime no direito brasileiro a adoção da doutrina de Dinamarco acerca dos escopos da jurisdição e da instrumentalidade do processo. $\mathrm{O}$ autor cita em sua obra quatro escopos principais: social, político, jurídico e processual. Esses escopos incluiriam os mais diversos objetivos da função jurisdicional, dentre eles o da aplicação correta do direito (escopo jurídico), a pacificação social por meio da resolução adequada de conflitos, dentre diversos outros. ${ }^{1}$

Para cumprir tais escopos, a função jurisdicional deve possuir certas características que vão além da justiça ou da correição das decisões. A jurisprudência deve ser coerente dentre os diversos órgãos julgadores sob pena de que sejam admitidas soluções diferentes para casos iguais apenas por serem julgadas por órgãos diferentes. Também as decisões judiciais, dentro de certo grau, devem ser previsíveis, sob pena de gerar insegurança e instabilidade generalizada em todos que dependam da aplicação da lei (ou seja, a sociedade como um todo).

A necessidade social, política e econômica de uma estabilidade jurisdicional se estende pela história, gerando reações diferentes em cada momento histórico. Foi uma das razões que levou às primeiras codificações, à unificação de ordenamentos jurídicos, e, como veremos, ao surgimento de diversas técnicas e institutos jurisdicionais. Atualmente no Brasil a estabilidade da jurisprudência tem sido objeto de grande interesse por doutrinadores, julgadores e legisladores.

Dentre os avanços realizados nos últimos anos temos as súmulas vinculantes (introduzidas por meio da Emenda Constitucional 45/2004); o incidente de resolução de demandas repetitivas nos tribunais superiores (Lei 11.672/2008); e, na maior reforma dos últimos anos, o novo Código de Processo Civil, que além de sedimentar e ampliar os institutos que lhe precederam, buscou lançar as bases e criar os instrumentos para um sistema de precedentes judiciais no direito brasileiro.

Porém, todas as medidas instituídas até o momento voltaram seu foco apenas para um dos componentes das decisões judiciais: a decisão sobre questões de direito. As súmulas vinculantes têm como objeto "a validade, a interpretação e a eficácia de normas

\footnotetext{
${ }^{1}$ DINAMARCO, Cândido Rangel. A instrumentalidade do processo. 15. ed. São Paulo: Malheiros, 2013.
} 
determinadas", cujo alto grau de abstração levou alguns doutrinadores a considerá-las verdadeiros atos normativos, ainda que diferente das leis propriamente ditas. ${ }^{2}$

Os recursos especial e extraordinário repetitivos, tanto na sua forma instituída pela Lei 11.672 quanto pela forma expandida do incidente de resolução de recurso repetitivo previsto no novo Código de Processo Civil, tendem também a fixar teses abstratas em casos que atingem o judiciário de forma massificada, para que todos os órgãos judiciais vinculados ao tribunal que fixar tal tese a apliquem posteriormente. E, por último, ao tentar lançar as bases de uma sistemática de precedentes no ordenamento jurídico brasileiro, a doutrina que se desenvolve em volta do novo Código de Processo Civil tem dado mais ênfase às questões de fato, ainda que para definir parâmetros de aplicação dos precedentes judiciais.

Porém, apesar de todos os avanços recentes que buscam introduzir mais de uma desejável estabilidade à atividade jurisdicional no Brasil, as decisões acerca de questões de fato têm sido deixadas em um indesejável segundo plano. Enquanto teses, súmulas e precedentes se multiplicam, sua aplicação não será suficiente para que haja a desejada estabilidade e previsibilidade das decisões judiciais se as partes não possuem parâmetros de como agir em juízo para demonstrar o suporte fático de seu direito ao julgador. De nada adianta a estabilização de teses sobre a aplicação do direito, se as decisões sobre questões de fato permanecem caóticas e aleatórias.

É evidente que as peculiaridades das situações de fato em cada processo têm o condão de levar a soluções diferentes. Decidir sobre questões de fato, ainda que sob um estado prevalecente de incerteza, ${ }^{3}$ é o dever do julgador. Porém, o que é lesivo ao ordenamento jurídico e à sociedade como um todo é quando não existem parâmetros concretos para a decisão sobre questões de fato, o que leva a desequilíbrios entre as partes nos processos, e incertezas em todo o sistema processual..

Dessa forma, os julgadores não conseguem construir parâmetros adequados para suas decisões. Os tribunais, ao realizar a revisão de um caso em que já houve um julgamento sobre questões de fato, não possuem parâmetros concretos para avaliar as decisões de primeiro grau. As partes, seus advogados e o Ministério Público não conseguem analisar de forma adequada os riscos de adentrar em litígio com base nas provas que possuem ou possam vir a produzir.

\footnotetext{
${ }^{2}$ RAMOS, E. da S. Ativismo judicial: parâmetros dogmáticos. São Paulo: Saraiva, 2010. p. 297.

${ }^{3}$ SAKS, M. J.; KIDD, R. F. Human information processing and adjudication: Trial by Heuristics. Law and Society Review, Salt Lake City, v. 15, n. 1, p. 123-160, 1981.
} 
Quando dois juízes ou tribunais, com base em acervos probatórios semelhantes aplicam parâmetros de suficiência probatória distintos acerca de uma questão de fato igual (ou semelhante), ocorre a mesma distorção verificada nos casos em que temos decisões contraditórias acerca da aplicação do direito. Isso porque, como ensina Taruffo, "uma decisão jurídica e justa somente pode fundar-se em uma valoração apropriada, exata e veraz dos fatos relevantes do caso". 4

Além disso, a escolha dos standards de prova aplicáveis (ou mesmo de sua ausência) possui um impacto significativo na função jurisdicional como um todo. Questões de minimização e distribuição de riscos, de estabilidade das decisões, e do próprio modo como os juízes decidem não podem ser ignoradas ao efetuar tal escolha

Dessa maneira, a ausência de parâmetros para decisões acerca de questões de fato é, por si só, um problema que deve ser enfrentado para que possamos evoluir a atividade jurisdicional em nosso ordenamento. E é um problema que deve ser analisado de forma cuidadosa, sob pena de regressar ao extremo de teorias irracionalistas ou idealistas acerca da verdade, ou de posições extremadas acerca da liberdade do julgador.

Encontrar uma solução para o problema acima não é uma tarefa fácil, e o tema ainda é pouco explorado em nossa doutrina e jurisprudência. Apesar de já existirem trabalhos de excelente qualidade sobre o tema, ${ }^{5}$ este ainda se encontra à margem das grandes discussões no direito brasileiro.

Essa relutância em enfrentar o tema possui raízes históricas e ideológicas profundas: em razão de nossa colonização as principais influências do direito brasileiro sempre foram os sistemas jurídicas da Europa continental, que em determinado momento histórico convergiram para a livre apreciação da prova como sistema (ou ausência de sistema) para a valoração dos elementos probatórios, com uma carga ideológica de contraposição aos sistemas autoritários onde havia a limitação do julgador enquanto regra.

\footnotetext{
${ }^{4}$ TARUFFO, Michelle. A prova. Tradução de João Gabriel Couto. São Paulo: Marcial Pons, 2014. p. 20.

5 Sobre o tema, conferir SILVEIRA, Daniel Coutinho da. Prova, argumento e decisão: critérios de suficiência para orientação dos juízos de fato no direito processual brasileiro. 2011. Dissertação (Mestrado em Direito Processual) - Faculdade de Direito, Universidade de São Paulo, São Paulo, 2011. Disponível em: <http://www.teses.usp.br/teses/disponiveis/2/2137/tde-24042012-113857/>. Acesso em: 27 jun. 2016. Também, TRENTO, Simone. Efetividade da tutela jurisdicional em matéria probatória: Standard e ônus da prova. 2012. Dissertação (Mestrado em Direito) - Universidade Federal do Paraná, Curitiba.
} 
Até hoje existe grande resistência em tentar estabelecer parâmetros ao julgador acerca de sua atividade de valoração das provas e decisão acerca de questões de fato. Expressões vazias como "o juiz é o destinatário da prova", "livre convencimento motivado" ou "persuasão racional" têm sido utilizadas para mascarar um modelo de efetiva discricionariedade judicial sobre questões de fato.

Tal discricionariedade é tão nociva quanto indesejável. Sob a sistemática atual, é perfeitamente possível que juízes adotem critérios de decisão personalíssimos e de controle impossível a casos iguais, que dependam de resolução de questão controvertida de fato, mesmo onde haja um acervo probatório idêntico. Em um exemplo, dois vizinhos poderiam sofrer o mesmo dano, produzir a mesma prova em conjunto e litigar sob os mesmos argumentos, ao final obtendo decisões distintas: o primeiro vizinho tem seu dano reconhecido e é indenizado, enquanto o segundo enfrenta uma sentença de improcedência por não provar os fatos constitutivos de seu direito pelo parâmetro escolhido pelo julgador.

E, ao realizar a escolha por um ou outro standard, sua utilidade e conformação aos fins almejados devem ser também analisadas. Apesar de possível em tese, é de pouca utilidade adotar o mesmo standard dos casos criminais aos casos cíveis, nos quais as razões políticas que permeiam cada sistema processual são absolutamente distintas. Também entre casos cíveis, é possível diferenciar entre classes de processos para aplicar standards distintos.

Por outro lado, permitir que o standard seja decidido (ou modificado) caso a caso é tão inefetivo como sua ausência; isso porque, os mecanismos de cognição utilizados pelos julgadores (decorrentes da psicologia humana, não necessariamente de um sistema de civil law ou common law) não permitem efetuar sua regulação de forma tão delicada.

Tal proposta não é um extremo de se retornar ao sistema de prova legal ou tarifada, mas apenas de criar linhas gerais a serem adotadas por juízes e patronos que os auxiliem a tomar decisões baseadas em elementos de prova de acordo com as peculiaridades de cada tipo de processo.

Também, não se trata do mero transporte de um instituto estrangeiro ao direito brasileiro. ${ }^{6}$ Ao tratar de fundamentos extralegais, extrapoláveis para outros ordenamentos jurídicos, e a partir destes propor soluções, a ideia é criar uma versão compatível com nosso ordenamento jurídico, a partir do qual possam ser atingidos os fins objetivados, ou

\footnotetext{
${ }^{6}$ WATANABE, Kazuo; GRINOVER, Ada Pellegrini. Recepção e transmissão de institutos processuais civis. Revista de Processo, v. 31, p. 143-154, 2006.
} 
mesmo identificar standards que já existam, e apenas sistematizar seu estudo, seus objetivos e sua aplicação.

\subsection{Principais questões a serem analisadas}

Para tentar esboçar tais linhas gerais, ou ao menos como estas podem ser instituídas pelos tribunais, este trabalho inicia analisando os institutos mais básicos a partir dos quais se desenvolve a atividade probatória judicial. Por essa razão, a primeira parte deste trabalho introduz as discussões acerca do papel dos fatos, da verdade e da prova no processo judicial, e fixa vários conceitos que serão utilizados no desenvolvimento da argumentação.

Em seguida introduziremos a ideia de "standards de prova" dos sistemas de common law (também denominados "modelos de constatação"). ${ }^{7}$ A partir de uma análise histórica de como os sistemas legais enfrentam a questão da prova suficiente, analisaremos a origem da distinção entre os sistemas de civil law e common law a partir do século XVIII, e as prováveis causas que levaram os sistemas a evoluir em caminhos divergentes acerca da apreciação da prova.

Analisaremos sua conformação no cenário atual, a partir do modelo americano e seus três standards principais (beyond a reasonable doubt, clear and convincing evidence $\mathrm{e}$ preponderance of the evidence), além de alguns comentários sobre o modelo do beweisma $\beta$ no direito alemão. Em seguida, serão analisadas as justificativas econômicas (minimização do risco de erro) e psicológicas (limitações cognitivas dos julgadores) que fundamentam a adoção dos standards de prova, e teceremos alguns comentários sobre a ideia de adoção de standards de prova com o fim de incentivar ou reprimir certas condutas pelos ordenamentos.

A terceira parte trará uma análise dos standards de prova como colocados no direito brasileiro. Argumenta-se que, apesar de seu estudo não haver sido sistematizado como no

\footnotetext{
${ }^{7}$ COSTA, Guilherme Recena. Livre convencimento e standards de prova. In: YARSHELL, Flávio Luis; ZUFELATO, Camilo (Org.). 40 anos da Teoria Geral do Processo no Brasil: passado, presente e futuro. 1.ed. São Paulo: Malheiros, 2013.
} 
sistema de common law, o direito brasileiro expressamente adota standards de prova, que podem ser sistematizados e estudados como tais. Analisaremos o exemplo mais comum, que são os standards utilizados nas tutelas provisórias: fumus boni iuris, verossimilhança, e probabilidade do direito; analisaremos as propostas doutrinárias de adoção de um standard distinto em processos sancionadores; e por último, discutiremos a adoção de um standard para as causas cíveis comuns.

Ao final será analisada a forma como o direito brasileiro lida com o risco da incerteza inerente às decisões acerca de questões de fato, por meio do instituto do ônus da prova. Serão identificadas as diferenças entre o instituto do ônus da prova em sua tradição continental, e o seu desenvolvimento nos países de tradição jurídica anglo-saxônica. Será analisada como as diferentes concepções de ônus da prova influenciam os procedimentos e as formas de julgar, e ao final, serão sugeridos alguns elementos de aproximação entre as ideias de ônus da prova em sua aplicação no direito brasileiro, a partir da ideia de standards de prova.

\subsection{Metodologia}

O método de abordagem a ser utilizado para a elaboração da dissertação será o indutivo, mediante o qual, partindo de dados particulares suficientemente constatados, infere-se uma verdade geral ou universal. Principalmente ao analisar aspectos psicológicos dos processos de decisão, utiliza-se como base experimentos realizados anteriormente e cujos resultados já foram compilados.

Como métodos de procedimento serão adotados concomitantemente os métodos histórico, funcionalista e comparativo. O primeiro consiste no encadeamento de fatos, usando a sequência temporal ou convivência de fatos no mesmo período de tempo. O segundo estuda a sociedade do ponto de vista de suas unidades. $\mathrm{O}$ último consiste na comparação dos fenômenos estudados com outros semelhantes em diversos momentos históricos.

As técnicas básicas de pesquisa adotadas são a bibliográfica e documental jurisprudencial. A pesquisa bibliográfica será desenvolvida a partir de obras de destaque quanto ao tema, e artigos científicos especializados, ambos dirigidos a públicos específicos, os operadores do direito. A pesquisa documental consistirá no estudo detido de documentos relevantes, como diplomas normativos referentes ao tema e jurisprudências atualizadas dos principais tribunais que se ocupam com esses problemas. 


\section{CONCLUSÃO}

Estudar institutos jurídicos de outros sistemas judiciais é sempre uma tarefa árdua. Todo e qualquer estudo deve possuir uma análise redobrada para evitar que sejam feitas transposições ou generalizações apressadas, que acabam por ruir em razão das particularidades de cada sistema.

Por essa razão, no presente trabalho buscamos analisar o instituto dos standards de prova a partir de seus fundamentos mais básicos, para compará-los com nosso sistema, e, a partir daí, verificar sua compatibilidade in abstrato.

Para isso, além de uma breve perspectiva histórica, que demonstrou que a divergência entre os sistemas de civil law e common law quanto aos standards se deu por razões históricas e particulares, mas não em razão da incompatibilidade absoluta entre os sistemas e o instituto, verificamos também que do modo como evoluiu, nosso princípio de liberdade da prova não é incompatível com um sistema de standards de prova.

Em seguida, a partir da análise de um sistema onde os standards já se consolidaram e são utilizados de forma reiterada há séculos, pudemos analisar como se dá a aplicação dos standards em casos concretos, seus requisitos essenciais e seus problemas. Enquanto questões como diferenças conceituais e falta de clareza nas instruções surgem como um obstáculo à sua aplicação efetiva, a tendência desses sistemas é a de, em conjunto com outras disciplinas, evoluir para tornar os standards mais acessíveis e efetivos.

Verificamos também que as justificativas doutrinárias e psicológicas adotadas nos sistemas de common law para a adoção de standards de prova são, em grande parte, independentes das particularidades daquele sistema. Questões como minimização dos custos dos erros ou prevenção de falsos positivos são justificativas normativas que se encaixam plenamente nos escopos de nosso ordenamento jurídico, principalmente se levarmos em conta que sempre haverão erros ao decidir sobre questões de fato.

Também as justificativas psicológicas sobre a aplicação dos standards para juízes e júris, e sobre como defini-los (em graus amplos ou mínimos de diferença) partem de lições da psicologia aplicáveis à humanidade em geral, podendo ser estudadas e aproveitadas em nosso sistema (ainda que seja desejável desenvolver nossos próprios estudos, que apontem as particularidades do sistema brasileiro). 
Por fim, após definir que as premissas básicas para a aplicação dos standards são compatíveis com o ordenamento jurídico brasileiro, pudemos analisar diversos institutos presentes em nossas leis e doutrina para perceber que não só os standards são compatíveis, mas já existem em nosso direito, ainda que sem essa classificação específica. Conceitos como fumus boni iuris e verossimilhança, revelam, em análise mais aprofundada, semelhança ou até mesmo identidade com os standards de common law.

Por último, a adoção dos standards é também complementada por um viés distinto da análise do ônus da prova. Quando admitimos os distintos graus de convencimento do juiz, e as variações nos standards, percebemos que o ônus da prova opera de forma distinta, já que a não persuasão que lhe é característica também se diferencia conforme o standard aplicável.

Dessa maneira, esperamos que esse estudo possa, ao fim, atingir seu objetivo: iniciar um estudo mais organizado e aprofundado dos standards de prova enquanto categoria no direito brasileiro para, em vez de realizar análises pontuais de institutos de diversas áreas do direito, esses possam ser compreendidos em uma perspectiva global e interdisciplinar. 


\section{BIBLIOGRAFIA}

ABE, Jair Minoro. Verdade Pragmática. Estudos Avançados, v. 5, n. 12, São Paulo, maio/ago. 1991.

ALCHOURRÓN, Carlos; BULGYIN, Eugenio. Introducción a la metodologia de las Ciencias jurídicas y sociales. Buenos Aires: Astrea, 1970.

ARISTOTELES. Metafísica. Tradução de Leonel Vallandro. Porto Alegre: Globo, 1969.

BENTHAM, J. The Works of Jeremy Bentham, published under the Superintendence of his Executor, John Bowring. Edinburgh: William Tait, 1838-1843. p. 343. Disponível em: <http://lf-oll.s3.amazonaws.com/titles/1923/Bentham\0872-06\_EBk\_v6.0.pdf>. Acesso em: 2 fev. 2016.

BERMAN, Mitchell N. Replay, 99 Cal. L. Rev. 1683 (2011). p. 1.711. Disponível em: <http://scholarship.law.berkeley.edu/californialawreview/vol99/iss6/6>. Acesso em: 29 out. 2017.

BLACKSTONE, William. Commentaries on the Law of England. Oxford: Clarendon Press, $1765 . \quad$ v. 1. Disponível em: <http://web2.uvcs.uvic.ca/courses/lawdemo/DOCS/BLACKSTN/B6367_7 3.HTM>. Acesso em: 25 set. 17.

BRASIL. Superior Tribunal De Justiça. Recurso Especial 1.672.891/SC. Relator: Ministro Hermann Benjamin. Setembro de 2017. Pesquisa de jurisprudência, Acórdãos. Disponível em <www.stj.jus.br>. Acesso em: 11 out. 2017.

Superior Tribunal de Justiça. Agravo Interno no Agravo em Recurso Especial 1.097.733/SP. Agravante: João Baptista Mateus de Lima. Agravado: Ministério Público Federal. Relatora: Ministra Assussete Magalhães. Brasília, setembro de 2017. Pesquisa de jurisprudência, Acórdãos. Disponível em <www.stj.jus.br>. Acesso em: 11 out. 2017.

Superior Tribunal de Justiça. Agravo Interno no Recurso Especial 1.528.837/SP. Agravante: Jose Carlos Mello Rego e Outros. Agravado: Ministério Público Federal. Relator: Ministro Francisco Falcão. Brasília, outubro de 2017. Pesquisa de jurisprudência, Acórdãos. Disponível em <www.stj.jus.br>. Acesso em: 15 nov. 2017.

Superior Tribunal de Justiça. Agravo Regimental no Recurso Especial 1.621.655/SP. Agravante: Ministério Público Federal. Luis Henrique Fernandes Rios. Relator: Ministro Joel Ilan Paciornik. Brasília, novembro de 2017. Pesquisa de jurisprudência, Acórdãos. Disponível em <www.stj.jus.br>. Acesso em: 11 dez. 2017.

BROOK, J. Inevitable errors: the preponderance of evidence standard in civil litigation. Tulsa Law Journal, v. 18, 1982, p. 79-109. 
BUSTAMANTE, Evanilda. A valoração racional das provas no processo judicial: uma aproximação ao tema. Disponível em: <http://www.publicadireito.com.br/artigos/?cod=531d29a813ef9471>. Acesso em: 24 nov. 2015.

CARNELUTTI, Francesco. A Prova Civil. Tradução de Lisa Pary Scarpa. 2. ed. Campinas: Bookseller, 2002.

CHOI, Yimoon. Jurors' Subjective Certainty and Standards of Proof: The Role of Emotion and Severity of Charge in Subjective Probability Judgment. Dissertação de PhD. Departamento de Psicologia, Universidade de Nebraska-Lincoln, 2013. Disponível em: <http://digitalcommons.unl.edu/psychdiss/61>. Acesso em: 10 jun. 2016.

CARPES, Artur Thompsen. O direito fundamental ao processo justo: notas sobre o modelo de constatação nos processos envolvendo as ações de improbidade administrativa. In: LUCON, Paulo Henrique dos Santos; COSTA, Eduardo José da Fonseca; COSTA, Guilherme Recena. Improbidade Administrativa: Aspectos processuais da Lei $\mathrm{n}^{\circ}$ 8.429/92. São Paulo: Atlas, 2015.

CINTRA, Antônio Carlos de Araújo. Comentários ao Código de Processo Civil: arts. 332 a 475. Rio de Janeiro: Forense, 2003.

CLERMONT, Kevin M. Standards of proof revisited. Vermont Law Review, v. 33, 2009.

Standards of decision in law: Psychological and logical bases for the standard of proof, here and abroad. Durham: Carolina Academic Press, 2013.

Trial by Traditional Probability, Relative Plausibility, or Belief Function? 66 Cas. W. Res. L. Rev. 353(2015). Disponível em: <http://scholarlycommons.law.case.edu/caselrev/vol66/iss2/5>. Acesso em: $1^{\circ}$ nov. 2017.

COSTA, Guilherme Recena. A ambivalência da ação de improbidade administrativa e sua conformação processual. In: LUCON, Paulo Henrique dos Santos; COSTA, Eduardo José da Fonseca; COSTA, Guilherme Recena. Improbidade Administrativa: Aspectos processuais da Lei no 8.429/92. São Paulo: Atlas, 2015.

. Livre convencimento e standards de prova. In: YARSHELL, Flávio Luis; ZUFELATO, Camilo (Org.). 40 anos da Teoria Geral do Processo no Brasil: passado, presente e futuro. 1.ed. São Paulo: Malheiros, 2013.

DAMASKA, Mirjan R. Evidence law adrift. New Haven: Yale University Press, 1997.

Rational and Irrational Proof Revisited. Faculty Scholarship Series. Paper 1577. Disponível em: 〈http://digitalcommons.law.yale.edu/fss_papers/1577>. Acesso em: 12 jul. 2017.

The Uncertain Fate of Evidentiary Transplants: Anglo-American and Continental Experiments. Faculty Scholarship Series. Paper 1576. 1997.

Truth in Adjudication. Faculty Scholarship Series, 1998. Paper 1575. Disponível em: <http://digitalcommons.law.yale.edu/fss_papers/1575>. Acesso em: 27 jun. 2016. 
DASTON, Lorraine. Classical Probability in the Enlightenment. Princeton: Princeton University Press, 1988.

DE GIL, Paula Viale. ¿La prueba es suficiente cuando es suficiente? Aproximación a la construcción de la decisión de suficiencia de la prueba en materia penal. Revista Pensar em Derecho, Buenos Aires, Eudeba, 2014.

DEMOUGIN, Dominique; FLUET, Claude. Deterrence VS. Judicial Error. A comparative view of standards of proof. Journal of Institutional and Theoretical Economics (JITE), v. 161, n. 2, jun. 2005.

DHAMKI, Mandeep K. et al. Instructions on Reasonable Doubt: Defining the Standard of Proof and the Juror's Task. Psychology, Public Policy and Law, v. 21, maio 2015.

DINAMARCO, Cândido Rangel. A instrumentalidade do processo. 15. ed. São Paulo: Malheiros, 2013.

Instituições de Direito Processual Civil. São Paulo: Malheiros, 2005. v. III.

ESTADOS UNIDOS DA AMÉRICA. 28 U.S. Code $§ 2244$ - Finality of determination.

28 U.S. Code $§ 2639$ - Burden of proof; evidence of value

. California Civil Jury Instructions (CACI)(2017). Disponível em: <https://www.justia.com/trials-litigation/docs/caci/200/201.html>. Acesso em: 3 nov. 2017.

. Corte de Apelações da Califórnia. Glage v. Hawes Firearms Co. (1990) 226 Cal.App.3d 314, 325 [276 Cal.Rptr. 430]. App. 2000)

Corte de Apelações do Tennesse. Fell v. Rambo, 36 S.W.3d 837, 847-48 (Tenn.

District court of Maine. 2017 revisions to pattern criminal jury instructions for the district courts of the first circuit. Disponível em: <http://www.med.uscourts.gov/pdf/crpjilinks.pdf>. Acesso em: 22 out. 2017.

. Federal Rules of Civil Procedure. Rule 50 - Judgment as a Matter of Law in a Jury Trial; Related Motion for a New Trial; Conditional Ruling.

. Judicial Council of California Civil Jury Instructions (CACI) (2016 edition), p. 118. Disponível em: <https://www.justia.com/trials-litigation/docs/caci/caci-2017edition.pdf $>$.

(1973)

Suprema Corte dos Estados Unidos. Keyes v. School District No. 1, 413 U.S. 189 
New York Unified Court System CJI and MC Committee. CJI2d[NY] Model Instructions: Final Instructions. Disponível em: <http://www.nycourts.gov/judges/cji/5SampleCharges/CJI2d.Final_Instructions.pdf>. Acesso em: 24 out. 2017.

Ninth Circuit Jury Instructions Committee. Manual of model jury instructions for the district courts of the ninth circuit. 2017 ed. Acessado em 20/07/2017. Disponível em: <http://www3.ce9.uscourts.gov/jury-

instructions/sites/default/files/WPD/Civil_Instructions_2017_9.pdf>.

. Primeiro Circuito. United States v. Van Anh, 523 F.3d 43, 58-59 (1st Cir. 2008).

Cir. 1995).

Quarto Circuito. Keeler Brass Co. v. Cont'l Brass Co., 862 F.2d 1063, 1066 (4 $^{\text {th }}$

- Suprema Corte dos Estados Unidos. Alaska Department of Environmental Conservation v. EPA, 540 U.S. 461 (2004) (1984)

Suprema Corte dos Estados Unidos. Colorado v. New Mexico 467 U.S. 310

. Suprema Corte dos Estados Unidos. Cruzan v. Director, Missouri Department of Health, 497 U.S. 261 (1990).

. Suprema Corte dos Estados Unidos. Director, Office of Workers' Compensation Programs v. Greenwich Collieries 512 U.S. 267 (1994)

. Suprema Corte dos Estados Unidos. Grogan v. Garner, 498 U. S. 279, 286 (1991);

. Suprema Corte dos Estados Unidos. In Re Winship, 397 U.S. 358 (1970).

. Suprema Corte dos Estados Unidos. Leland v. Oregon, 343 U.S. 790 (1952).

. Suprema Corte dos Estados Unidos. Microsoft Corp. v. i4i Limited Partnership (564 U.S. 91 (2011)).

. Suprema Corte dos Estados Unidos. Schaffer v. Weast, 546 U. S. 49, 56 (2005);

$\overline{(1958)}$.

. Suprema Corte dos Estados Unidos. Speiser v. Randall, 357 U.S. 513, 525-526

. Suprema Corte dos Estados Unidos. Victor v. Nebraska, 511 U.S. 1, 5-6 (1994).

Terceiro Circuito. El v. Southeastern Pennsylvania Transportation Authority, 3rd Cir., No. 05-3857 (March 19, 2007).

FERRER BELTRÁN, Jordi. La Valoración Racional de la Prueba, Marcial Pons, Madrid, 2007.

FERREIRA, Willian Santos Ferreira. Princípios fundamentais da prova cível, São Paulo, RT, 2014.

GASCÓN ABELLÁN, Marina. Sobre la posibilidad de formular estándares de prueba objetivos. Doxa - Cuadernos de Filosofía del Derecho, v. 28, p. 127-139. 
GODOI BUSTAMANTE, Evanilda N. Decidir sobre los Hechos: un estudio sobre la valoración racional de la prueba judicial. 1. ed. Madri: Bubok, 2013

GOLDSCHMIDT, James. Derecho procesal civil. Tradução espanhola da segunda edição alemã de Leonardo Prieto. Barcelona: Labor, 1936.

GOMES FILHO, Antônio Magalhães. Notas sobre a terminologia da prova (reflexos no processo penal brasileiro). In: YARSHELL, Flávio Luiz; MORAES, Maurício Zanoide de. (Org.). Estudos em homenagem à professora Ada Pellegrini Grinover. São Paulo: DPJ, 2005 .

GONZÁLEZ LAGIER, D. Argumentación y prueba judicial. In: FERRER BELTRÁN, Jordi et al. Estudios sobre la prueba. México: Universidad Nacional Autónoma de México, 2006.

GRECO, L. O conceito de prova. In: MARINONI, L. G. (Ed.). Estudos de Direito Processual Civil. São Paulo: Revista dos Tribunais, 2005

HAACK, Susan. Filosofia das lógicas. Tradução de Cezar Augusto Mortari e Luiz Henrique de Araujo Dutra. São Paulo: Unesp, 2002.

Nothing fancy: Some simple truths about Truth and the Law. In: Evidence Matters: Science, Proof and Truth in the Law. New York: Cambridge University Press, 2014.

HAPE, Jaag. Law and defeasability. Artificial Intelligence and Law, v. 11, p. 221-243, 2003.

HERBERMANN, Charles G. et al. (Eds.). The Catholic Encyclopedia. New York: Robert Appleton Company, 1909. v. V.

HOROWITZ, I. A.; KIRKPATRICK, L. C. A concept in search of a definition: the effects of reasonable doubt instructions on certainly of guilt standards and jury verdicts. Law and Human Behavior, v. 20, p. 655-670, 1996.

JAMES JR., Fleming. Burdens of Proof. Virginia Law Review, v. 47, n. 51, 1961.

JUSTEN FILHO, Marçal. Curso de direito administrativo. 2. ed. São Paulo: Saraiva, 2006.

KAHNEMAN, Daniel; FREDERICK, Shane. Representativeness revisited: Attribute substitution in intuitive judgment. In: KAHNEMAN, Daniel; GILOVICH, Thomas; GRIFFIN, Dale W. (Eds.). Heuristics and biases. New York: Cambridge University Press, 2012.

. Thinking, fast and slow. 2. ed. Nova York: Farrar, Straus and Giroux, 2013.

; TVERSKY, Amos. Prospect Theory: an analysis of decision under risk. Econometrica, v. 47, n. 2, p. 263-291, mar. 1979. 
KAYE, David H. Do we need a calculus of weight to understand proof beyond reasonable doubt? 66 B.U.L. Rev. 657 (1986), p. 657-672

. The Error of Equal Error Rates. Law, Probability and Risk, v. 1, p. 3-8, jul. 2002.

KERR, N. L. et al. Guilt beyond a reasonable doubt: effects of concept definition and assigned decision rule on the judgments of mock jurors. Journal of Personality and Social Psychology, v. 43, p. 282- 394, 1976.

KIRKHAM, R. L. Teorias da Verdade: Uma introdução crítica. Tradução de Alessandro Zir. São Leopoldo: Unisinos, 2003.

KNIJNIK, Danilo. A prova nos juízos cível, penal e tributário. Rio de Janeiro: Forense, 2007.

LANGBEIN, John H. The Historical Foundations of the Law of Evidence: A view from the Ryder Sources. Faculty Scholarship Series. Paper 551, 1996. Disponível em: < http://digitalcommons.law.yale.edu/fss_papers/551>. Acessado em: 10 out. 2017.

LEUBSDORF, John. The Surprising History of the Preponderance Standard of Civil Proof, 67 Fla. L. Rev. 1569 (2016). Disponível em: <http://scholarship.law.ufl.edu/flr/vol67/iss5/2>. Acessado em: 20 out. 2017.

LIEBMAN, Enrico Tullio. Manual de Direito Processual Civil. São Paulo: Malheiros, 2005.

LIMA, Matheus. Prova suficiente e o julgamento por ônus da prova. In: XXVI CONGRESSO NACIONAL DO CONPEDI, 2017, São Luís. Processo, jurisdição e efetividade da justiça III - XXVI Congresso Nacional do CONPEDI São Luís/MA. Florianópolis: CONPEDI, 2017. p. 152-172.

LOCKE, John. Ensaio acerca do entendimento humano. Tradução de Anoar Aiex. São Paulo: Nova Cultural, 1999.

LUCON, Paulo Henrique dos Santos. Compra de votos, direito sancionador e ônus da prova. In: TAVARES, André Ramos; AGRA, Walber de Moura; PEREIRA, Luiz Fernando (Org.). O direito eleitoral e o novo Código de Processo Civil. 1.ed. Belo Horizonte: Fórum, 2016. v. 1.

; COSTA, Guilherme Recena. A prova e a responsabilidade de terceiros contratantes com o Poder Público na ação de improbidade administrativa. In: LUCON, Paulo Henrique dos Santos; COSTA, Eduardo José da Fonseca; COSTA, Guilherme Recena. (Org.). Improbidade administrativa: aspectos processuais da Lei ${ }^{\circ}$ 8.429/92. 2. ed. São Paulo: Atlas, 2015.

LOEVINGER, Lee. Standards of Proof in Science and Law. Jurimetrics, v. 32, n. 3, 1992.

MACÊDO, Lucas Buril de; PEIXOTO, Ravi. Ônus da prova e sua dinamização. Salvador: Jus Podivm, 2014.

MAITLAND, Frederic W.; POLLOCK, Frederick. The History of English Law Before the Time of Edward I. Cambridge University Press: Cambridge, 1898. v. 2. 
MARINONI, Luiz Guilherme. Antecipação da Tutela. 11. ed. São Paulo: Revista dos Tribunais, 2009.

; ARENHARDT, Sérgio. Prova e convicção: de acordo com o CPC de 2015. 3. ed. São Paulo: Revista dos Tribunais, 2015.

. Formação da convicção e inversão do ônus da prova segundo as peculiaridades do caso concreto. Revista Magister de Direito Civil e Processual Civil, Porto Alegre, n. 13, p. 60-72, 2006.

; ARENHART, Sérgio Cruz. Processo cautelar. 6. ed. São Paulo: Revista dos Tribunais, 2014.

MCBRIDE, Ennis. Is the civil "higher standard of proof" a coherent concept? Law, probability and risk, v. 8, p. 323-351, 2009. Disponível em: <https://academic.oup.com/lpr/article-abstract/8/4/323/925840>. Acesso em: 3 nov. 2017.

MCCAHEY, John. The burdens of persuasion and production. Proof: The journal of the trial evidence committee, v. 16, n. 3, 2008.

MCCORMICK, Charles T. McCormick on Evidence. 3. ed. St. Paul: West Publishing Co., 1984.

MILLER, Alan D.; PERRY, Ronen. The Reasonable Person. New York University Law Review, v. 87, p. 323-392, 2012.

The Magical Number Seven, Plus or Minus Two: Some Limits on Our Capacity for Processing Information. The Psychological Review, 1956, v. 63, p. 81-97. Disponível em: <http://www.musanim.com/miller1956/>. Acesso em: 15 ago. 2017.

MITIDIERO, Daniel. Tendência em matéria de tutela sumária: da tutela cautelar à técnica antecipatória. Revista de Processo, v. 197.

Comentário ao art. 300. In: WAMBIER, Teresa Arruda Alvim et al. Breves Comentários ao Novo Código de Processo Civil. São Paulo: Revista dos Tribunais, 2016.

MOREIRA, José Carlos Barbosa. Julgamento e ônus da prova. In: Temas de Direito Processual. São Paulo, Saraiva, $2^{\text {a }}$ Série, 1980.

ORLOFF, Neil; STEDINGER, Jery. A framework for evaluating the preponderance-ofthe-evidence standard, 131 U. Pa. L. Rev., 1159, 1983.

PEIRCE, Charles Sanders. How to make our ideas clear. Popular Science Monthly 12, jan. 1978, p. 286-302.

PEREIRA, Renato Machado. Concepção semântica da verdade segundo Alfred Tarski. Dissertação (Mestrado) - Universidade Federal de São Carlos, UFSCAR, 2009. 
PEYRANO, Jorge W. La regla de la carga de la prueba enfocada como norma de clausura del sistema. Revista de Processo, v. 35, n. 185, jul. 2010, p. 107-116.

PINTO, Marcos. Reflexões sobre improbidade administrativa, ônus da prova, modelos de constatação e nota sobre o NCPC. In: BEDAQUE, José Roberto dos Santos; CINTRA, Lias Carolina Batista; EID, Elie Pierre. (Org.). Garantismo Processual: garantias constitucionais aplicadas ao processo. 1.ed. Brasília: Gazeta Jurídica, 2016. v. 1.

PIRES, Líbia da Graça. Teoria da distribuição dinâmica do ônus da prova no processo do trabalho. 2011. Tese (Doutorado em Direito do Trabalho) - Faculdade de Direito, Universidade de São Paulo, São Paulo, 2011. Disponível em: <http://www.teses.usp.br/teses/disponiveis/2/2138/tde-04052012-101854/>. Acesso em: 28 maio 2015.

PORTER, Stephen; BRINKE, Leanne Ten. Dangerous decisions: A theoretical framework for understanding how judges assess credibility in the courtroom. Legal and Criminological Psychology, n. 14.

RAMOS, E. da S. Ativismo Judicial: parâmetros dogmáticos. São Paulo: Saraiva, 2010.

SAKS, Michael J.; SPELLMAN, Barbara. The psychological foundations of evidence law. New York: New York University Press, 2016.

; KIDD, R. F. Human information processing and adjudication: Trial by Heuristics. Law and Society Review, Salt Lake City, v. 15, n. 1, p. 123-160, 1981.

SCHAUER, Frederick. Is Defeasibility an Essential Property of Law? Disponível em: $\langle$ http://www.umiacs.umd.edu/ horty/courses/readings/schauer-defeasibility.pdf $>$. Acesso em: 27 nov. 2015.

SCHWARTZ, David L.; SEAMAN, Christopher B. Standards of Proof in Civil Litigation: An Experiment from Patent Law, 26 Harv. J. L. \& Tech. 429 (2013).

SCHWEIZER, Mark. Loss aversion, omission bias, and the civil standard of proof. In: MATHIS, Klaus (ed.). European perspectives on behavioral law and economics. Cham: Springer, 2015.

The civil standard of proof - what is it, actually? The international journal of evidence and proof, v. 20, n. 3, 2016.

SILVA, Clovis V. do Couto e. A teoria das ações em Pontes de Miranda. Revista de informação legislativa, v. 25, n. 100, p. 249-256, out./dez. 1988.

SILVA, Ovídio A. Baptista da. Teoria Geral do Processo Civil. 3. ed. São Paulo: Revista dos Tribunais, 2002.

Do processo cautelar. Rio de Janeiro: Forense, 2001.

SILVEIRA, Daniel Coutinho da. Prova, argumento e decisão: critérios de suficiência para orientação dos juízos de fato no direito processual brasileiro. 2011. Dissertação (Mestrado em Direito Processual) - Faculdade de Direito, Universidade de São Paulo, São Paulo, 
2011. Disponível em: <http://www.teses.usp.br/teses/disponiveis/2/2137/tde-24042012113857/>. Acesso em: 27 jun. 2017.

SUN, Yanlong et al. Probabilistic Judgment by a Coarser Scale: Behavioral and ERP Evidence. Proceedings of the Twenty-sixth Annual meeting of the Cognitive Science Society, 2004. Disponível em: <http://citeseerx.ist.psu.edu/viewdoc/download?doi=10.1.1.306.9799\&rep=rep1\&type=pdf $>$. Acessado em: 15 nov. 2017.

TANFORD, J. Alexander. The Law and Psychology of Jury Instructions, 69 Neb. L. Rev., 1990. Disponível em: <http://digitalcommons.unl.edu/nlr/vol69/iss1/4>. Acesso em: 10 nov. 2017.

TARUFFO, Michele. Evidence, Truth, and the Rule of Law. Revista de Processo, v. 39, n. 238, p. 87-98, dez. 2014.

. La prueba de los hechos. Madri: Trotta, 2003.

2003, p. 666.

Rethinking the standards of proof. American Journal of Comparative Law, v. 51, . A prova. Tradução de João Gabriel Couto. São Paulo: Marcial Pons, 2014.

jan./jun. 2013, p. 420-431.

THEODORO JUNIOR, Humberto. Curso de Direito Processual Civil - Processo de Execução e Cumprimento da Sentença, Processo Cautelar e Tutela de Urgência. 48. ed. Rio de Janeiro: Forense, 2013. v. II.

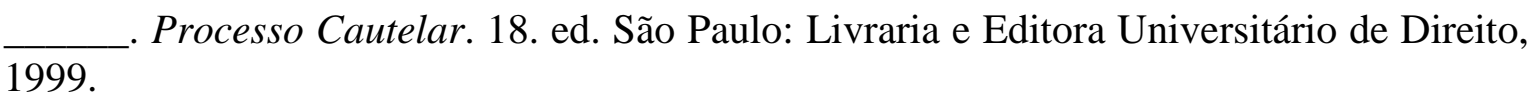
Prova - Princípio da Verdade Real - Poderes do Juiz - Ônus da Prova e sua eventual inversão - provas ilícitas - Prova e coisa julgada nas ações relativas a paternidade (DNA). Revista Brasileira de Direito de Família, v. 3, p. 5-23, 1999.

TORRES, Cláudio; NEIVA, Elaine Rabelo. Psicologia Social: Principais temas e vertentes. São Paulo: Artmed Editora, 2011.

TRENTO, Simone. Efetividade da tutela jurisdicional em matéria probatória: Standard e ônus da prova. 2012. Dissertação (Mestrado em Direito) - Universidade Federal do Paraná, Curitiba.

Os standards e o ônus da prova: suas relações e causas de variação. Revista de Processo, v. 226, dez. 2013.

V.H.L. Burden of Proof. Michigan Law Review, v. 17, n. 3, jan. 1919, p. 264-266. 
VAN DER POL, Ruth; PETROV, Anton. Searching for Truth in civil process: The Netherlands and Russia. Russian Law Journal, v. 3, n. 1, 2015, p. 110-132.

WALSH, D. Fact. The Journal of Philosophy, v. 40, n. 24, p. 645-654, 1943.

WALTER, Gerhard. Libre apreciación de la prueba. Bogotá: Temis, 1985.

WALTON, Douglas N. Burden of proof. Disponível em: <http://www.dougwalton.ca/papers\%20in\%20pdf/88burden.pdf>. Acesso em: 5 jun. 2015.

WATANABE, Kazuo. Cognição no Processo Civil. 4. ed. São Paulo: Saraiva, 2012.

; GRINOVER, Ada Pellegrini. Recepção e transmissão de institutos processuais civis. Revista de Processo, v. 31, p. 143-154, 2006.

; GRINOVER, Ada Pellegrini; NERY JUNIOR, Nelson. Código Brasileiro de defesa do consumidor comentado pelos autores do anteprojeto. 10. ed. Rio de Janeiro: Forense, 2011. v. I.

WHITMAN, James Q. The Origins of "Reasonable Doubt". Faculty Scholarship Series. Paper 1. P. 38. Disponível em: <http://digitalcommons.law.yale.edu/fss_papers/1>. Acesso em: 20 jul. 2016.

WIGMORE, John Henry. Principles of Judicial Proof. Boston: Little, Brown and Company, 1913.

YARSHELL, Flávio Luiz. Antecipação da prova sem o requisito da urgência e o direito autônomo à prova. São Paulo: Malheiros, 2009.

ZAMIR, Eyal; RITOV, Ilana. Loss aversion, omission bias, and the burden of proof in civil litigation. Journal of legal studies, v. 41, jan. 2012, p. 165-207. 